\title{
New estimates of eco-intensity considering the hazardous industrial pollution accumulation
}

\author{
Irina Glazyrina ${ }^{1,2}$ and Andrey Chavkin ${ }^{2, *}$ \\ ${ }^{1}$ Russian Academy of Sciences, Siberian Branch, 16a, Nedorezova St., 672014, Chita, Russia \\ ${ }^{2}$ Transbaikal State University, 30, Alexandro-Zavodskaya St., 672039, Chita, Russia
}

\begin{abstract}
The paper proposes a new approach to environmental and economic assessments based on the author's economic and mathematical model that takes into account the accumulation of hazardous pollutants in natural environments. It also presents the results of calculations showing the dynamics of the increase in the negative impact depending on the natural assimilation of pollutants. This data can be considered as a quantitative assessment of the "environmental cost" that society pays by consuming goods the production of which is accompanied by the accumulation of longlived pollutants. It is shown that this "price" can very significantly exceed the eco-intensity calculated without taking into account the accumulation of pollutants. Thus, the accumulation of pollutants as a result of economic activity is an important factor in the context of the impact on the ecological and economic balance. The implementation of the results obtained in the adjustment of the calculations of payments for negative environmental impact is proposed: to set payments per unit of production which are not proportional to emissions, but proportional to the eco-intensity calculated according to the proposed methodology. In this case, the accumulation of harmful substances in natural environments, the added value of production and the timing of project implementation will be taken into account. This corresponds to the concept of "green" economy, which provides the growth of well-being and quality of life with the maximum possible reduction of the negative anthropogenic pressure and improvement of the quality of the environment.
\end{abstract}

\section{Introduction}

Among the environmental problems, an important place is occupied by the pollution with dangerous substances that slowly decompose in the natural environment in the process of natural assimilation. Their negative impact increases as they accumulate in the environment. Nevertheless, the production of many products that humanity cannot abandon at the present time is accompanied by emissions of such dangerous substances.

Emissions of particularly hazardous substances occupy an important place among these problems. In the Russian regulatory documents, they are classified as the 1 st and 2 nd hazard classes. Cadmium, lead, chromium compounds, benz(a)pyrene are highly toxic substances of the 1st hazard class. For example, cadmium can accumulate in the body and in the soil. The

\footnotetext{
*Corresponding author: pletnev.dmitri@gmail.com
} 
toxic effect of cadmium occurs when it is contained in the soil in an amount of $3 \mathrm{mg} / \mathrm{kg}$, in the biomass of plants not less than $0.4 \mathrm{mg} / \mathrm{kg}$. The half-life of cadmium in the body is 10 years (http://www.chelpogoda.ru/pages/607.php). The carcinogenic effect of cadmium is known. It accumulates in the kidneys, and its content can increase up to 1,000 times during a human life. Another substance that accumulates in organisms of hazard class 1 (in terms of its effect on the human body) is lead and its compounds.

Problems arise not only when it comes to individual unique productions. In this case, it would be possible to solve it with special measures that ensure security in each specific industrial project. Some of the most dangerous pollutants, (these include, for example, benzo(a)pyrene), are common. Benzo(a)pyrene is constantly being released into the atmosphere from power plants, emissions of automobiles, railway transport. The total emissions of this substance worldwide from fuel combustion are estimated at 2.6 thousand tons per year, and from waste incineration -1.3 thousand tons. (http://www.chelpogoda.ru/pages/607.php) In order to assess the risk of such emissions, it is sufficient to compare these volumes with the lethal doses of benz(a)pyrene when ingested by living organisms, which do not exceed 15 micrograms $/ \mathrm{kg}$. (http://base.garant.ru/71929532/53f89421bbdaf741eb2d1ecc4ddb4c33). It does not only enters the from the atmosphere, as it accumulates mainly in the soil and subsequently then enters the plant tissues. With further movement along the trophic chain, its concentration usually increases significantly.

Therefore, an important task is to create economic mechanisms that stimulate the maximum reduction in the emission of such substances. For these purposes, it is necessary to obtain quantitative estimates of the ecological and economic balance, taking into account the processes of accumulation of pollutants. This is the main purpose of this work.

We used the author's economic and mathematical model [1], which allows us to assess the damage from the accumulation of pollutants depending on the rate of their assimilation in the natural environment. In this work, it is shown that the total environmental damage from industrial projects significantly depends on the timing of their implementation. The analysis of the model allowed us to establish that for a wide range of projects there is a "moment of conflict of interests" between the society and business. At this point, the society is interested not only from an environmental, but also from an economic point of view in terminating the project, while it is in the interests of business to continue it. Large deposits of gold, coal, and polymetallic ores are being developed in many regions of Siberia and the Russian Far East. Persistent pollutants are often found in the dumps, emissions and discharges of these enterprises, as well as in industrial waste landfills. As a rule, their beneficiaries are companies registered outside the mining regions (often in offshore areas), and the negative consequences go to the local population. Thus, we observe situations of "ecologically unequal exchange" [2], the parameters of which need to be evaluated in quantitative terms.

\section{Materials and methods}

A full description of the author's mathematical model, which is the basis of this work, is presented in [1]. To quantify the degree of non-compliance of real damage with estimates based on specific emissions, the category of "eco-intensity" was used, which is the basis of various approaches to environmental and economic analysis [3-5]. For the purposes of this work, an adaptation of this concept to the assessment of the emission of hazardous substances, taking into account their accumulation in the environment, is proposed. The calculations were performed using MathCad. Methodologically, the work follows the general approaches of ecological economics, which are most fully presented in the book [6]. 


\section{Results}

Traditionally, eco-intensity is defined as the quantitative ratio between the negative impact on the environment from economic activity and its economic result. Gross value added is most often considered as economic results. When calculations are made at the macro-or meso-economic level, it is usually gross domestic product (GDP) or gross regional product (GRP). If the question of the relationship between the environmental burden and the standard of living is studied, then the income of citizens can be considered as an economic result. If we are considering a specific industrial project, the eco-intensity can be determined by the following formula:

$$
E=\frac{\text { The amount of pollution per year }}{\text { value added per year }}=\frac{e}{l}
$$

where $e$ is the volume of annual emissions per unit of output,

$l$ - is the value added per unit of output.

However, if the pollutants slowly decompose in the environment and gradually accumulate, then every year the real negative impact per unit of production will increase. In order to take into account this accumulated impact, we will use a special mathematical model.

Below is the model description, based on the approach from [1].

For simplicity, let's assume that the project provides for a constant volume of production over the entire implementation period, with a constant added value per unit of production.

Let's also assume that pollutants are released with each unit of production, and these emissions are constant throughout the life of the project. Therefore we use:

$N$ - the project implementation period,

$r$ is the discount rate

$\delta$ - the proportion of pollutants that decompose during the year,

$L-$ annual value added.

It is shown in [1] that the amount of pollution accumulated over $\mathrm{N}$ years is calculated by the formula:

$$
Z(N)=e \sum_{t=1}^{N} \frac{1-(1-\delta)^{t}}{\delta}
$$

The current estimate of the added value for $\mathrm{N}$ years, calculated by the formula

$$
Y(N)=\sum_{t=1}^{n} \frac{1}{(1+r)^{t}} L
$$

One can calculate the negative impact indicator per unit of output for the entire life of the project:

$$
\bar{E}(N)=\frac{Z(N)}{Y(N)}=\frac{e}{\delta \mathrm{L}} \frac{\sum_{t=1}^{N}\left[1-(1-\delta)^{t}\right]}{\sum_{t=1}^{N} \frac{1}{(1+r)^{t}}}
$$

We will call $E(N)$ an indicator of eco-intensity, taking into account the accumulation of pollution. We can consider this value as the "ecological price" that a society pays for producing and consuming material goods, the production of which damages its habitat, per unit of production.

It is clear that as the duration of the project increases, this indicator increases for all parameters. To assess how significant, the factor of accumulation of pollutants can be, some model numerical calculations were carried out. The value of $\delta=1$ corresponds to the case when the pollutant decomposes within one year, and the accumulation of pollutants does not 
occur. One of the variants of this calculation $(L=1, e=1)$ is shown in Fig. 1. It shows how the importance of the parameter $\delta$ increases with the increase in the project lifetime.

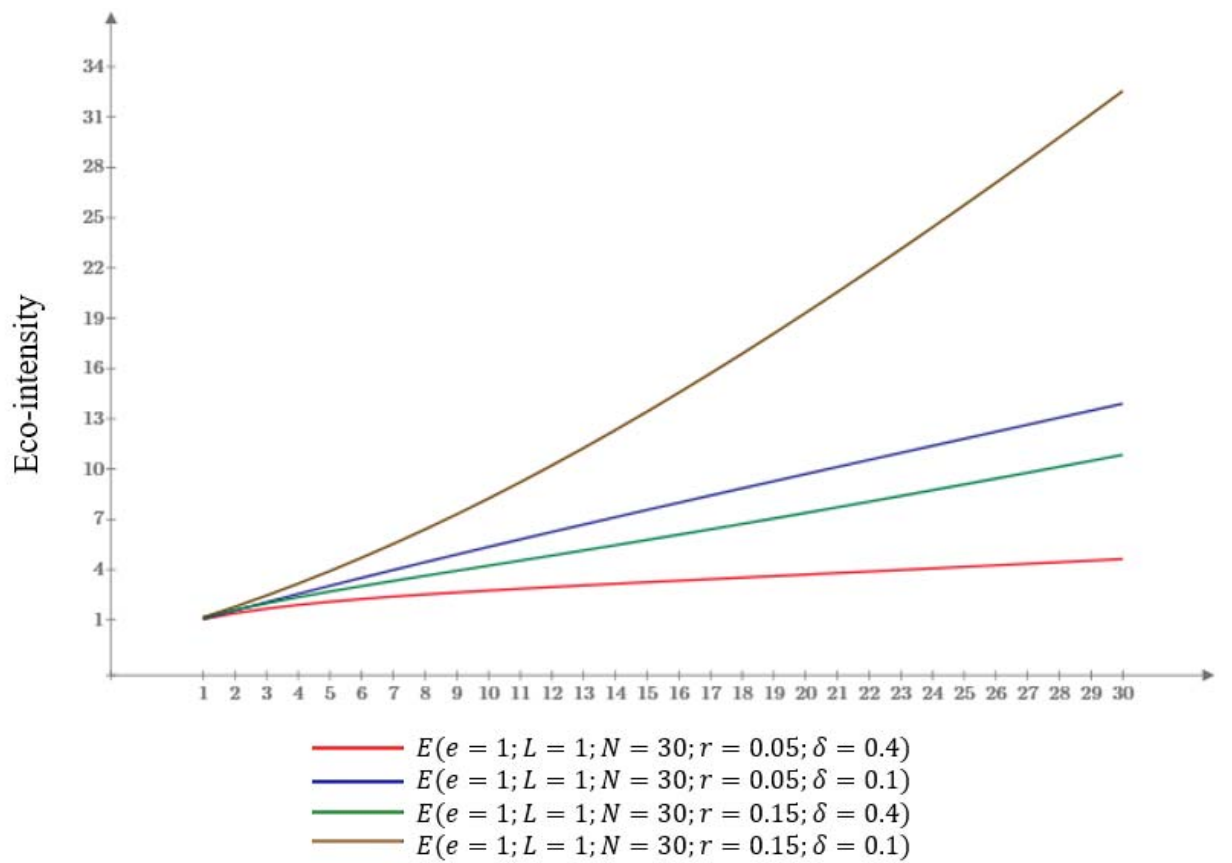

Fig. 1. Dynamics of the eco-intensity indicator, taking into account the accumulation of pollutants, depending on the rate of assimilation of the pollutant in the environment and the increase rate. Calculations of the authors.

If we are talking about relatively rapidly decomposing pollutants $(\delta=0.4$, that is, decomposition occurs in 2.5 years), then at a percentage rate of 0.05 over a time horizon of 30 years, $\mathrm{E}(\mathrm{N})$ is about 4.6 times higher than the eco-intensity value without taking into account the pollution. However, for long-lived pollutants $(\delta=0.1$, that is, the decomposition of the pollutant occurs in 10 years) this excess is already 13 times as high.

Figure 1 also shows us the dependence of the eco-intensity indicator, taking into account the accumulation of pollution, on the increase rate, that is, on the "price of money" for a particular project. With an increase in the value of money, the benefits of society, which in our model are quantified by the value added, obviously decrease, and therefore the ecointensity increases.

Figure 2 shows the results of model calculations of the dependence of eco-intensity, taking into account the accumulation of pollutants, on the increase rate for long-lived pollutants: $\mathrm{e}=1, \mathrm{~L}=1, \mathrm{~N}=30, \mathrm{r} \in[0 ; 0.5], \delta=0.1$. It clearly demonstrates how much it can increase depending on the "cost of money". An increase in the interest rate, of course, does not affect the total amount of emissions. But it reduces the amount of benefits which are received by the society and, thus, increases their "environmental cost". 


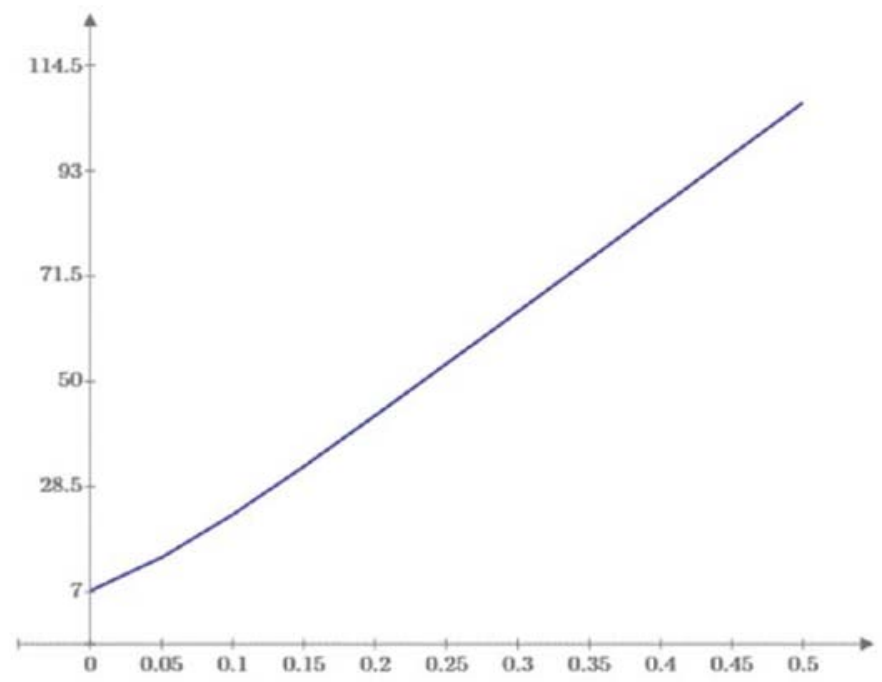

Fig. 2. The dependence of the eco-intensity $\mathrm{E}(\mathrm{N})$ on the interest rate $\mathrm{r}(\mathrm{e}=1, \mathrm{~L}=1, \mathrm{~N}=30, \delta=0.1)$. Calculations of the authors.

Over a long time horizon, the dependence of eco-intensity, taking into account the accumulation of long-lived pollutants, on added value, is significant. This is illustrated in Fig. 3. It presents the results of calculations for two production processes, the added value of which differs by 5 times. For high-value-added products, the eco-intensity of the accumulation of long-lived pollutants increases at a much slower rate as the project life increases than for low-value-added products.

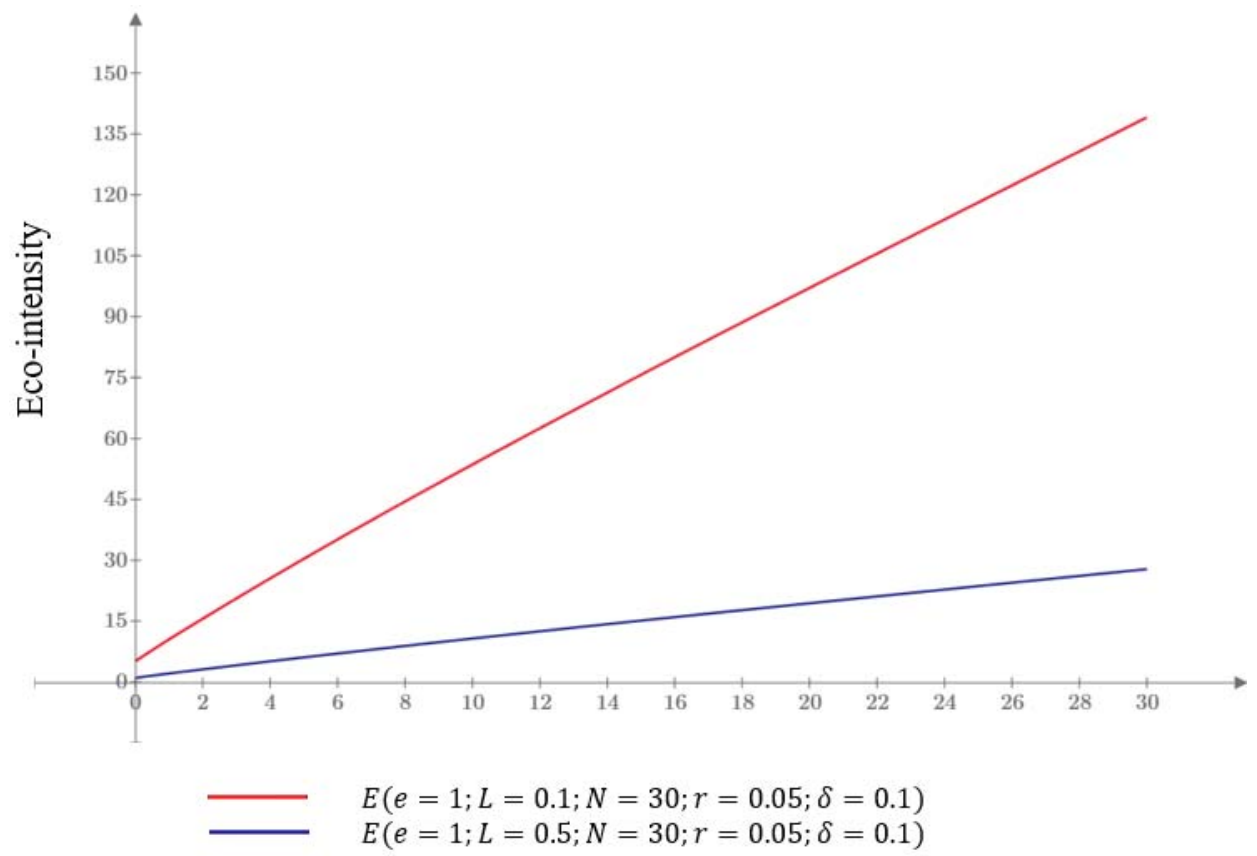

Fig. 3. The dependence of eco-intensity, taking into account the accumulation of long-lived pollutants, on the added value. Authors' calculations. 
Tables 1 and 2 show the data for calculating the eco-intensity indicator depending on the value added and the rate of assimilation of pollutants over a 30 -year horizon. The results of Table 1 show its (model) values when it is possible to attract "low-cost" investments - for example, in the case of public-private partnerships or investor participation in state programs for the development of territories. We see that, depending on the value added, they can differ by an order of magnitude for any variants of the rate of assimilation of pollutants. This suggests that from the point of view of the ecological and economic balance, the use of public finance for production with high added value can be much more effective than for raw materials projects. In practice, it turns out that in the regions of the Far East, raw materials projects or low-conversion projects are much more often supported by the state [7]. This is due to the fact that one of the most important indicators for access to preferential tax conditions and priority access to resources is the volume of attracted investments. Mineral resource projects usually require high costs for overburden operations and the creation of production infrastructure, and therefore receive advantages in various programs.

Table 1. Eco-intensity indicators for projects with "low-cost investments": $r=0.05$. Authors calculations.

\begin{tabular}{|c|c|c|c|c|c|c|c|c|c|c|}
\hline \multicolumn{8}{|c|}{ Coefficient of assimilation of the pollutant in the environment $(\mathbf{r}=\mathbf{0 . 0 5}$; $=\mathbf{1}$; N=30) } \\
\hline $\begin{array}{c}\text { Value } \\
\text { added per } \\
\text { a unit of } \\
\text { output }\end{array}$ & 0.1 & 0.2 & 0.3 & 0.4 & 0.5 & 0.6 & 0.7 & 0.8 & 0.9 & 1 \\
\hline 1 & 13.909 & 8.458 & 5.999 & 4.635 & 3.773 & 3.180 & 2.748 & 2.419 & 2.160 & 1.952 \\
\hline 2 & 6.954 & 4.229 & 3.000 & 2.317 & 1.886 & 1.590 & 1.374 & 1.210 & 1.080 & 0.976 \\
\hline 3 & 4.636 & 2.819 & 2.000 & 1.545 & 1.258 & 1.060 & 0.916 & 0.806 & 0.720 & 0.651 \\
\hline 4 & 3.477 & 2.115 & 1.500 & 1.159 & 0.943 & 0.795 & 0.687 & 0.605 & 0.540 & 0.488 \\
\hline 5 & 2.782 & 1.692 & 1.200 & 0.927 & 0.755 & 0.636 & 0.550 & 0.484 & 0.432 & 0.390 \\
\hline 6 & 2.318 & 1.410 & 1.000 & 0.772 & 0.629 & 0.530 & 0.458 & 0.403 & 0.360 & 0.325 \\
\hline 7 & 1.987 & 1.208 & 0.857 & 0.662 & 0.539 & 0.454 & 0.393 & 0.346 & 0.309 & 0.279 \\
\hline 8 & 1.739 & 1.057 & 0.750 & 0.579 & 0.472 & 0.398 & 0.344 & 0.302 & 0.270 & 0.244 \\
\hline 9 & 1.545 & 0.940 & 0.667 & 0.515 & 0.419 & 0.353 & 0.305 & 0.269 & 0.240 & 0.217 \\
\hline 10 & 1.391 & 0.846 & 0.600 & 0.463 & 0.377 & 0.318 & 0.275 & 0.242 & 0.216 & 0.195 \\
\hline
\end{tabular}

Table 2 shows the results of calculations for projects with more "expensive" money. This can be a model description of the situation when an investor attracts commercial loans. In this case, the indicators of the ecological and economic balance deteriorate several times. 
Table 2. Eco-intensity indicators for projects with "expensive investments": $r=0.15$. Authors calculations.

\begin{tabular}{|c|c|c|c|c|c|c|c|c|c|c|}
\hline \multicolumn{7}{|c|}{ Coefficient of assimilation of the pollutant in the environment (r=0.15; e=1; N=30) } \\
\hline $\begin{array}{c}\text { Value } \\
\text { added } \\
\text { per a } \\
\text { unit } \\
\text { of } \\
\text { output }\end{array}$ & 0.1 & 0.2 & 0.3 & 0.4 & 0.5 & 0.6 & 0.7 & 0.8 & 0.9 & 1 \\
\hline 1 & 32.564 & 19.803 & 14.045 & 10.851 & 8.833 & 7.446 & 6.434 & 5.664 & 5.058 & 4.569 \\
\hline 2 & 16.282 & 9.901 & 7.023 & 5.426 & 4.417 & 3.723 & 3.217 & 2.832 & 2.529 & 2.285 \\
\hline 3 & 10.855 & 6.601 & 4.682 & 3.617 & 2.944 & 2.482 & 2.145 & 1.888 & 1.686 & 1.523 \\
\hline 4 & 8.141 & 4.951 & 3.511 & 2.713 & 2.208 & 1.861 & 1.608 & 1.416 & 1.264 & 1.142 \\
\hline 5 & 6.513 & 3.961 & 2.809 & 2.170 & 1.767 & 1.489 & 1.287 & 1.133 & 1.012 & 0.914 \\
\hline 6 & 5.427 & 3.300 & 2.341 & 1.809 & 1.472 & 1.241 & 1.072 & 0.944 & 0.843 & 0.762 \\
\hline 7 & 4.652 & 2.829 & 2.006 & 1.550 & 1.262 & 1.064 & 0.919 & 0.809 & 0.723 & 0.653 \\
\hline 8 & 4.071 & 2.475 & 1.756 & 1.356 & 1.104 & 0.931 & 0.804 & 0.708 & 0.632 & 0.571 \\
\hline 9 & 3.618 & 2.200 & 1.561 & 1.206 & 0.981 & 0.827 & 0.715 & 0.629 & 0.562 & 0.508 \\
\hline 10 & 3.256 & 1.980 & 1.405 & 1.085 & 0.883 & 0.745 & 0.643 & 0.566 & 0.506 & 0.457 \\
\hline
\end{tabular}

\section{Discussion and Conclusion}

Traditionally, the relationship between economic benefits and environmental impacts (sometimes referred to as "environmental costs" or" environmental bads") is determined by the eco-intensity of production [8], i.e. equality (1). This approach is based on most systems of taxes and payments for negative environmental impacts, including the" carbon " tax, which became the subject of active discussion after the Paris Agreement [9, 10]. Carbon dioxide $\mathrm{CO} 2$, strictly speaking, is not a "pollutant", but the consequence of its accumulation in the atmosphere is the negative consequences associated with climate change. Therefore, these outliers can also be analysed in the framework of the presented model.

In our calculations, we attempted to quantify the "environmental price" that society pays by consuming goods whose the production of which is accompanied by the accumulation of long-lived pollutants. We have shown that this "price" can very significantly exceed the ecointensity calculated without taking into account the accumulation of pollutants. Thus, the accumulation of pollutants as a result of economic activity is an important factor in the context of the impact on the ecological and economic balance.

The calculation of environmental taxes and payments for enterprises that produce harmful emissions and discharges, in proportion to their volumes, does not take into account the factor of accumulation of pollutants in the environment. This form of implementation of the "polluter pays" principle, as shown in [1], can lead to a conflict of interests between society and private business. This reduces their effectiveness as regulatory tools. Business initiatives do not receive sufficient incentives to reduce emissions of long-lived pollutants, for environmental modernization in order to dispose of them and neutralize them.

In Russia, the owner of most natural resources is the state, that is, society as a whole. Therefore, it has the right to insist that resources are used in its interests. In addition, the high quality of the environment itself is a valuable public good and affects the quality of life [11]. 
Therefore, it would be reasonable to set payments for negative environmental impacts not in proportion to emissions per unit of output, but in proportion to the eco-intensity calculated according to the proposed methodology and reflected in the formula (4). In this case, the accumulation of harmful substances in natural environments, the added value of production and the timing of project implementation will be taken into account. This corresponds to the concept of "green" economy, which provides for the growth of well-being and quality of life with the maximum possible reduction of the negative anthropogenic load [12] and improvement of the quality of the environment.

\section{Acknowledgement}

The work was carried out in accordance with the State task for the Basic research programs of Siberian Branch of Russian Academy of Sciences.

\section{References}

1. I.P. Glazyrina, V.V. Glazyrin, S.V. Vinnichenko, Ecological Economics 59(3), 324-330 (2006)

2. I.P. Glazyrina, Transbaikal State University Journal 22(3), 93-100 (2016)

3. Environmental quality of the growth indicators for regional economy (NIAPriroda, Moscow, 2005)

4. S.N. Bobylev, O.V. Kudryavtseva, Ye.Yu. Yakovleva, Economy of Region 2, 148-159 (2015)

5. I.A. Zabelina, Economic and Social Changes: Facts, Trends, Forecast 12(1), 241-55 (2019)

6. H. Daly, J. Farley, Ecological economics: principles and applications (Island Press, Washington, 2003)

7. N.E. Antonova, N.V. Lomakina, Economic and social changes: facts, trends, forecast 11(1), 43-56 (2018)

8. M. de Haan, Accounting for goods and for bads: Measuring environmental pressure in a national accounts framework (M. de Haan, Voorburg, 2004)

9. Z.E. Gevrek, A. Uyduranoglu, Ecological Economics 118(3), 186-197 (2015)

10. J.K. Boyce, Ecological Economics 150(4), 52-61 (2018)

11. E.V. Ryumina, Ecological aspects of the assessment of quality of life Economy of Region 12(4), 1113-1122 (2016)

12. United Nations Environment Programme (UNEP). Driving a green economy through public finance and fiscal policy reform (2010) http://www.unep.org/greeneconomy/Portals/88/documents/ger/GER_Working_Paper_ Public_Finance.pdf 